\title{
ASPEK MORAL DAN NILAI-NILAI SOSIAL DALAM LIRIK-LIRIK LAGU REGGAE YANG DINYANYIKAN OLEH DEN BASITO
}

\author{
Erni Fatmawati, M. Shoim Anwar \\ Pendidikan Bahasa dan Sastra Indonesia, Fakultas Keguruan dan Ilmu Pendidikan, \\ Universitas PGRI Adi Buana Surabaya \\ ernifatmawati06@gmail.com, shoimanwar@yahoo.com
}

\begin{abstract}
The aspects of moral and social values are also many contained in any reggae song lyrics. Reggae song lyrics have a message about the behaviors of society and always uphold high human values. Because breath laden reggae lyrics that contain the struggle and the liberation of the weak from the authorities. Reggae music, the appellation of the rastaman, has become a new form of subculture in this country, where the young people determine and classifies themselves. Just how social observers and the members of the community to understand with the culture that they choose in order to avoid misrepresentation harmful to them. Data used in the study is the aspect of moral and social values. The sources of data are from the lyrics of the song sung by Den reggae Basito, books, internet, and Rastafaria group. Data collection technique in this study is transcription technique transform of oral into written data. While the methods used to analyze the data in this research is descriptive qualitative method. Based on the result of analysis the lyrics song sung by den Basito, in this study explained that every reggae song sung by Den Basito also has the meaning contained. In any lyrics, Den Basito tries to convey moral and social values in society today. Political world also become inspiration of making the lyric song. Den Basito wants to convey the natural beauty that we have if we respect for each other. In the lyrics, contain many meanings such as loyalty, religion, morality, politics, knowledge, beauty, and social value.
\end{abstract}

Keywords: Moral, Social Song Lyrics

\section{PENDAHULUAN}

Aliran reggae mulai berkembang pula tapi masih kurang populer dengan musik-musik lainnya. Musik reggae masih samar-samar di telinga masyarakat Indonesia.

Memasuki tahun 2000-an reggae sudah sangat berkembang, dengan adanya Mbah Surip dengan lagu yang ringan dengan diiringi musik yang kalem, Mbah Surip memperkenalkan pada masyarakat luas musik genre yang baru ditelinga masyarakat luas, yaitu aliran reggae yang berjudul "Tak Gendong", "Bangun Tidur", "I Love You Full”.

Perkembangan musik reggae Indonesia bisa dikatakan dalam kondisi di atas angin. Hampir tiga hingga empat even dapat terselenggara dalam setiap minggunya dan puluhan ribu pemuda pemudi di Indonesia ikut berpartisipasi dalam setiap evennya. Bisa dikatakan musik reggae merupakan musik yang paling digandrungi oleh pemuda pemudi Indonesia di era ini dibandingkan genre musik lainnya. 
Nafas reggae yang sarat akan lirik-lirik yang berisi tentang perjuangan dan pembebasan kaum yang lemah dari penguasa. Sudah seharusnya menjadi darah daging rakyat reggae Indonesia juga para musisi yang kini dianggap rakyat Reggae Indonesia telah popular.

Musik reggae itu terkenal dengan musik "santai", tapi maksudnya bukan masa bodoh dan tidak peduli terhadap lingkungan justru malah sebaliknya. Biasanya juga orang yang suka musik ini orang yang cinta damai dan suka ketenangan

Menurut Bertens (1993:9) sebagai refleksi atas moralitas perilaku manusia, etika mempunyai tradisi yang panjang.

Di zaman kita sekarang minat terhadap etika tidak berkuranng, tapi justru bertambah besar. Kata-kata seperti "etika", "etis", dan "moral" tidak terdengar dalam ruang kuliah saja dan tidak menjadi monopoli kaum cendekiawan. Diluar kalangan intelektualpun sering disinggung tentang hal-hal seperti itu. Memang benar, dalam obrolan di pasar atau di tengah penumpang-penumpang angkutan umum kata-kata itu jarang sekali muncul. Tapi saat membuka majalah, hampir setiap hari kita menemui kata-kata tersebut. Berulang kali menemukan kalimatkalimta semacam ini: " dalam dunia bisnis etika merosot terus", "etika dan moral perlu ditegaskan kembali”. Dalam pidato-pidato para pejabat pemerintahan juga banyak menggunakan kata etika.

Den Basito seorang pria yang memiliki segudang talenta, pria kelahiran di kota Kediri, 1 Juni 1979 ini melahirkan banyak karya yang memukau. Pria yang memilki ciri unik ini adalah salah satu penggagas dari paguyuban reggae atau biasa disebut PARE, dan telah banyak menggelar beberapa event di kota Pare, Kediri, dan sekitarnya. Dengan kesederhanaannya Den Basito menjelma menjadi musisi yang memeberikan warna baru dalam dunia musik di Indonesia yang beraliran di reggae. Dan saat dia menyanyi di atas panggung, Den Basito selalu berkata 'AMAN MAN'. Den basito juga menggelar konser di Tangerang, yang diselenggarakan oleh PARMI (Paguyuban Reggae Musik Indonesia), yang bertema 'Bersih Pantai Teluk Awur'. Kebanyakan lagu Den Basito bertemakan alam, sosial dan cinta.

Dari musik rege yang kalem, membuat orang yang mendengarnya merasa tenang dan merileksasikan otak agar tidak terlalu tegang. Ini membuat anak muda bisa meredam emosi mereka yang meluap-luap, seperti dalam lagu "Anak Alam" yang berbunyi "//Coba dengarkan bisikan sang alam/deburan ombak menghantam batu karang/ Hembusan angin

tenangkan jiwa.../oowyooyoo//”. Tak jarang juga Den basito menyindir tentang moral para pejabat, dengan menggunakan bahasa yang sederhana agar bisa dengan mudah dimengerti oleh anak muda.

Keistimewaan seni musik, semua karyanya dapat dimengerti oleh semua orang diseluruh dunia seperti misalnya lagu yang dimainkan bercorak riang gembira atau bernada sedih pilu atau bersemangat gairah seperti lagu Reggae. Unsur-unsur pada reggae terdapat pada alat musik reggae, salah satu alat musik reggae yang bernama jimbei, alat musik pukul yang persis dengan gendang ini memiliki bentuk yang lonjong dan dikalungkan untuk membawa jimbei.

Ruang lingkup penelitian ini secara ideal mengkaji tentang aspek moral dalam lirik lagu dan nilai sosial dalam lirik lagu. Agar tidak terjadi penyimpangan saat pembahasan. 
Penelitian ini diharapkan dapat menambah pengetahuan mengenai studi analisis terhadap sastra Indonesia terutama dalam musik reggae dan penelitian ini diharapkan mampu memberikan pengertian tentang musik beraliran reggae yang mengandung pesan moral, dan sosial yang dikemas dengan bahasa yang biasa dipakai sehari-hari agar anak muda dan masyarakat umum mudah memahami pesan yang terkandung didalamnya.

\section{METODE PENELITIAN}

Pendekatan kualitatif adalah suatu pendekatan dalam melakukan penelitian yang berorientasi pada gejala-gejala yang bersifat alamiah karena orientasinya demikia, maka sifatnya natural dan mendasar atau bersifat alamiah yang hanya bisa dilakukan langsung ke objek penelitian. Oleh sebab itu penelitian semacam ini disebut dengan field study (http://mulyajho.blogspot.com/2012/08/materi tentang-pendekatan-kualitatif.html) diakses, 28 Agustus 2014 Pukul 09.30.

Penelitian ini merupakan penelitian deskriptif kualitatif dengan menggunakan teknik transkripsi yang bertujuan untuk mengetahui aspek moral dan nilai sosial dalam lirik lagu reggae yang dinyanyikan oleh Den Basito. Teknik transkripsi adalah langkah untuk mengubah data lisan menjadi tulisan. (Suwardi , 2009:96).

Data dalam penelitian adalah aspek moral dan nilai sosial. Sumber data untuk melancarkan penelitian ini adalah lirik-lirik lagu reggae yang dinyanyikan Den Basito, dengan kata-kata yang mendayu-dayu, sehingga pesan yang disampaikan melewati lagu-lagu yang dinyanyikannya tersampaikan secara jelas. Ada 19 lagu yang telah Den Basito ciptakan

\section{PEMBAHASAN}

Dalam bab ini peneliti akan membahas permasalahan-permaslahan yang telah disebutkan diperumusan masalah dengan memberikan kutipan-kutipan lirik

Deskripsi Aspek moral yang berada di dalam lirik lagu reggae yang dinyanyikan Den Basito Dalam beberapa lirik lagu reggae yang dinyanyikan oleh Den Basito, ada beberapa lirik yang membicarakn tentang keadaan aspek moral dikalangan anak muda zaman sekarang seperti ada dalam beberapa lirik, moral dibagi menjadi 4 golongan yaitu moral msyarakat, moral larangan, moral aturan, moral adat istiadat, larangan, moral aturan, moral adat istiadat.

\section{Aspek moral msyarakat}

Aspek moral masyarakat adalah nilai yang berhubungan dengan kehidupan, sifat-sifat yang ada di kehidupan msyarakat.

\section{ANAK ALAM}

//Hingga datang nafsu manusia-manusia serakah yang tak peduli hancurkan alamku yang indah/Mengoyak nadi bumi pertiwi jangan biarkan ini terjadi//

Maksud dari kutipan lirik di atas adalah orang yang melakukan illegal logging secara besaran-besaran yang sedang terjadi di Kalimantan, dan bukan hanya itu. Den basito juga ingin mengungkapkan ketidak pedulian manusia terhadap lingkungan sekitar.

KONGKALIKONG

//Diputar diputar-putar kongkalikong kongkalikong/Cokot-cokotancokot-cokotan saling tuduh saling gigit/Cokot-cokotan saling caplok// 
Maksud dari penggalan lirik di atas adalah perbuatan para petinggi petinggi yang selalu tidak fear dalam menjalankan tugas-tugas yang dimiliki, mereka hanya bersenang senang. Tidak ragu-ragu untuk menyingkirkan seseorang yang bisa menghalangi obsesi dan kepentingan pribadi yang dapat memusakan diri mereka.

LIRIS (Lintingan Rokok Istimewa)

//Hanya kau yang tersisa/Temani disetiap waktuku/Liris kepergianku yang manis/Liris tegakan aku saat menangis/Liris ingatkanku akan indahnya dunia/l

Maksud dari kutipan lirik di atas adalah kebanyak orang-orang yang merasa letih dan ingin menghilangkan penat, sebagian besar mereka menghilangkan dengan cara merokok. Dan sebagian besar terbukti bahwa saat merokok bisa menyegarkan dan menghilangkan penat dari segala aktivitas.

LAPENDOS (Lelaki Pendosa)

//Bulan menyapa/Bulan merangka pelan jauh di angkasa/Para lelaki duduk dalam lingkaran/Mainkan gelas di tangan, dengan obrolan/Sesekali tertawa bersama/Ada yang terdiam memandang ruang hampa entah apa/Yang risaukan hatinyal/

Maksud dari kutipan lirik lagu di atas keseharian yang selalu dilakukan para lelaki pada waktu malam hari. Mereka bercakap-cakap dan membahas sesuatu yang santai dengan minuman keras yang mendampingi mereka.

\section{Aspek moral larangan}

Aspek moral larangan adalah sesuatu yang tidak boleh dilakukan karena dipandang tabuh.

\section{KUMPUL KEBO}

//Belum nikah sudah serumah/Saling panggil mama dan papa/Masih pacaran seperti nikah/Apa zaman sudah berubah/Kumpul kebo biasa/Bukan kumpul kebo beneran/Kumpul kebo biasa/Ternyata kok kumpul kebo beneran//

Maksud dari kutipan lirik lagu di atas adalah tentang kebiasaan yang sedang terjadi di abad-2000, dimana akhir-akhir ini hampir di seluruh dunia tampak kecendrungan masyarakat, terutama kaum muda, untuk membebaskan diri dari norma-norma lama di bidang seksual.

\section{KUMPUL KEBO}

//Dari pada kita kumul kebolebih baik nikah beneran/kita bukan kebo/bukan kebo bule/kita bukan bule/l

Disini dimaksudkan mengingatkan pada anak-anak remaja yang zaman sekarang berkiblat ke cara berpacaran seperti orang barat padahal kita ini orang timur yang memiliki unggah-ungguh (sopan santun). Dan di Negara Indonesia di larang, juga di haramkan oleh agama tapi kenapa terus dilanggar.

\section{SAMPAI KAPAN CAH AYU}

//Ojo buang waktumu pirang taun aku nunggu/Aku wes ora kuat nandang kangen ning dadaku/Aku wes pengen nyanding sliramu dadi duwekku/l

Maksud dari kutipan teks tersebut adalah Den basito ingin mengungkapkan rasa rindu yang bergejolak kepada sang kekasih. Karena penantian yang lama tiada kepastian akan menjadi miliknya seutuhnya atau tidak, dikarenakan tidak pernah bertemu.

\section{Deskripsi Nilai-nilai sosial yang berada di dalam lirik lagu reggae yang dinyanyikan Den Basito}


Di dalam lirik lagu reggae yang diciptakan Den Basito juga mengandung unsur-unsur sosial, meskipun para rastafaria yang terkenal dengan sikap yang cuek dan santai, mereka juga peduli akan sekitar dan menghormati setiap tindak tutur seseorang.

\section{Nilai sosial pengetahuan}

Nilai pengetahuan adalah nilai yang didapat dari pengalaman atau proses belajar.

AMINDAVA

//Ribuan tahun kita belajar/Mencari tahu apa, mengapa, dan bagaimana/Amindava amindava pada waktu/pada ruang dan tekanan/Pikirkanlah yang mengendalikan semual/

Maksud dari penggalan lirik "Amindava" adalah kadang manusia menjalani hidup dengan tidak tahu apa yang dicari, mengapa harus menjalani hidup dengan aturan, bagaimana akhir dari perjalanan mereka.

\section{Nilai sosial religius}

Nilai sosial religious yang merupakan nilai keagamaan tertinggi dan hukumnya mutlak. Nilai ini juga ada didalam lirik lagu reggae yang dinyanyikan oleh Den Basito.

\section{LAPENDOS}

//Lelaki penuh dosa yang taka ada pilihan lainnyal dia dia lelaki penuh dosa ingin bebaskan dirinya/dia dia lelaki penuh dosa akankah bisa akankah bisa akankah bisa diterim/lelaki penuh dosa coba padamkan neraka dihatinyall

Maksud dari penggalan lirik lagu dari "Lapendos" yang dinyanyikan oleh Den Basito adalah lelaki yang selama hidupnya selalu berpesta pora dengan minuman ini dinyatakan pada penggalan lirik //mainkan gelas ditangan dengan obrolan// lelaki ini menyesali apa yang telah dia perbuat. Lelaki yang ingin memperoleh pengampunan tapi lelaki ini masih, ragu apakah bisa memperoleh pengampunan.

\section{NYANYIAN LIRIH}

//hitam putih warna hidup ini/Yakinkah kita tuk serahkan semua padanya/yakinkah kita tuk serahkan padanya/Hilang/Hakimi kami dengan kesadaran/Hukum kami dengan ampunan/Hukum kami dengan kebahagiaan//

Maksud dari penggalan lirik lagu dari "Nyanyian Lirih" yang dinyanyikan oleh Den Basito adalah meskipun terkadang hidup ini tidak mnyenangkan dan tidak seperti keinginan kita, kita harus tetap percaya bahwa akan ada yang namanya kebahagiaan.

\section{Nilai sosial kepribadian}

Nilai sosial kepribadian adalah niali-niali yang membentuk karakter manusia. Yang dibagi beberapa yang dapat membentuk karakter manusia yaitu lingkungan, emosi, kreativitas, gagasan, ide.

HAI

//Darahku telah kau renangi/Selami seluruh urat nadi/Kau dekap erat jantungku/ Bersemayam di sana selamanyal saat waktu terus bergerak /Pecahkan keegoanku/Ramah sikap kau melihatku/Saatku terjatuh/Saatku terjatuh//

Maksud dari penggalan lirik lagu di atas adalah seseorang yang telah jatuh cinta kepada pasangannya yang teramat dalam, jiwa raganya telah dia dedikasikan kepada pasangannya.

\section{LIRIS}


//Kucurahkan sambut gelapnya malam/hanya kau yang tersisa/temani setiap waktuku/liris kepergianku yang manis/Liris tegakkan aku saat menangis/Liris ingatkanku akan indahnya dunia/l

Maksud dari penggalan lirik di atas adalah hanya sebatang rokok yang mampu menyemangati hidupnya, yang bisa membuat dia bahagia saat dia sedang sedih, dan sebatang rokok itu adalah temannya yang bisa berbagi waktu kegembiraan dengannya.

KANJENG MAMI

//Yang bisa bikin kita so happy/Wellcome to selamat datang/How are you apa kabarmu/I love you kanjeng mami//

Maksud dari penggalan lirik di atas adalah menggambarkan sosok wanita jawa yang memiliki jabatan tinggi sehingga dipanggil kanjeng mami. Sosok kanjeng mami ini adalah sosok wanita yang menyenangkan dan disegani oleh karyawannya.

RINDU INI

//Dalam sepinya waktu/Lelah aku menunggu/Kapan tiba saatnya aku bertemu/Sekedar melepas rindu/Sekedar untuk sesaat merengkuh dan memelukmu/Kukabarkan pada angina, pada malam dan bintang kutunggu engkau datang//

Maksud dari penggalan lirik ini adalah dimana seorang kekasih sangat merindukan kekasihnya yang jauh dari dirinya, karena terlalu lama berpisah dia merasa sepi meski di tengah keramaian.

KABAR GUE

//Kubicara pada pada malam/Bicara tentang bintanng/Uye/Tajuk dan cintaku yang terbuang/Yang dinodai dilukai/Kau korbankan/Kau tinggalkan/Kau hinakan/Kau kecewakan/Bila kau ingat diriku/Itulah kabar dariku/Bila kau ingat dariku//

Maksud dari penggalan lirik lagu reggae ini adalah tentang kekecewaan seseorang, tentang penghianatan. Pengorabanan yang telah dia berikan dibalas dengan kekecewaan yang mendalam.

SAHABAT

//Senyum sapa sahabat semua/Cukup kuat tuk sembuhkan luka/Kita berpelukan tajamkan ingatan/Bahwa kita tak sendiri.../Terimakasih sahabat/Masih ku temui dirimu../Trima kasih semua/Telah berjuang bersama sama../Trimakasi sahabat/Kita masih terus bersama'/Saat kita tertekan oleh kerasnya kehidupan/Ee.//

Maksud dari penggalan lirik lagu di atas adalah tentang arti sebuah persahabatan, dimana nilai persahabatan yang tulus bisa menjadi sebuah obat bagi temannya

\section{SANTAI}

//Di sini kita bebas/Teriak kelaut lepas/Dan kita nikmati hidup ini//

Maksud dari kutipan lirik di atas adalah kebebasan hidup yang tanpa terikat penuh dengan kebebasan. Laut adalah lambang dari ketenangan dimana tidak ada yang mngatur akan bagaimana arus gelombang bergerak, maksud di kutipan ini juga sama mereka ingin bebas tanpa ada yang mengatur tentang kehidupan mereka.

\section{Nilai sosial keindahan}


Nilai sosial keindahan adalah nilai yang berasal dari ungkapan-ungkapan perasaan kagum akan keindahan, contohnya kepada lawan jenis, alam, benda, dan lain-lain.

\section{TERLANJUR}

//Putri yang cantik dengarkan suaraku/Putri yang cantik inginku memelukmu dan bawamu kehidupku/Ada diotakku senyum manismu dan membuatku terjatuh, terjatuh//

Maksud dari penggalan lirik di atas adalah seseorang memiliki cinta yang tidak tersampaikan, hanya hasrat dan jiwanya sendiri yang merasakan gelora asmara yang membara pada jiwanya.

\section{SANG PENARI}

//Sementara pelangi bercahaya dengan sinar matahari/Yang menepi/Pada langit putih jingga disenyumnya/Kau gandeng butiran hujan menjamah bumi//

Maksud dari penggalan lirik di atas adalah menggambarkan suasana pada saat hujan dimana pelangi akan muncul disetiap hujan reda, dan saat itu digambarkan pelangi belum muncul pada kalimat //Yang menepi//. //pada langit putih jingga disenyumnya// disini menceritakan suasana pada saat itu sore hari.

\section{SAMPAI KAPAN CAH AYU}

//Tak sayangi sliramu tulus sing soko atiku/Tak trisnamu sliramu ikhlas jero ning dadaku/Senajan mergo jarang ketemu ning aku bakal tansah nunggu/l

Maksud dari penggalan lirik lagu ini adalah ungkapan persaan sayang (trisna) yang besar meskipun jarang berjumpa rasa sayang tidak akan hilang dan akan menunggu sampai kekasih hati datang.

ANAK ALAM

// Coba dengarkan bisikan sang alam/Coba dengarkan nyanyian satwa liar/Siulan angin desirkan kerinduan...akan indahnya alam kita/Coba dengarkan bisikan sang alam,.deburan ombak menghantam batu karang/Hembusan angin tenangkan jiwa...oowyooyoo/Oh indahnya laut kita...//

Maksud dari penggalan lirik lagu ini Den Basito ingin menyampaikan bahwa alam kita juga berbicara, alam kita ini juga memiliki jiwa meski dengan bahasa yang berbeda.

GAJAH KUPU-KUPU

//Gajah kupu" terbang rendah didepanku/Aku mengejarmu jangan lari dariku/Gajah kupu kupu menari" dimataku/Kuingin menyentuhmu jangan lari dariku/Kuingin tidur nggak mikir kamu/Kuingin duduk tanpa ada wajahmu/Kuingin berjalan dan nggak mikir kamu/Kungin hidup tanpa mikir tentang kamu/l

Maksud dari penggalan lagu di atas adalah tentang usaha seseorang meraih apa yang diinginkan tapi sangat susah didapatkan. Sampai seseorang itu lelah atau putus asa, ingin melepaskan harapan itu.

VESPA TUA

//Vespa tua bentukmu aku suka/Sangat menantang, vespaku berlari kencang/Vespa tua bentukmu aku suka/Sangat menggoda, idola tua dan muda/l

Maksud dari penggalan lirik lagu di atas adalah sebuah benda yang menjadi kebanggaan sepanjang masa, dari golongan tua sampai golongan muda. Vespa adalah barang yang antik untuk saat ini dan vespa adalah kendaraan yang menjadi simbol anak-anak reggae. 


\section{SARAN}

Berdasarkan temuan penelitian ini, penulis menyarankan sebagai berikut

a. Diharapkan untuk penelitian ini dapat meningkatkan dan memperluas pemahaman tentang lagu reggae yang banyak mengandung makna nilai kehidupan.

b. Diharapkan hasil penelitian ini dapat meningkatkan pengetahuan bagi pembaca tentang aspek moral dan nilai-nilai sosial di dalam lagu reggae.

\section{DAFTAR PUSTAKA}

Bertens, K. 1997. Etika. Jakarta: Pt. Gramedia.

Budiono, Sunu Catur. Rohmawati, Dyah. Prayitno, Lidya Lia. Retnani, Dwi. Zaman, Qomaru. Mastuti, Ending. Prayitno, Sunyoto Hadi. 2014. Penulisan Skripsi Dan Artikel Ilmiah. Surabaya: Adi Buana Surabaya.

Endraswara, Suwardi. 2009. Metodologi Penelitian Folklor. Jakarta: PT. Buku Kita.

Fajar, Adib. 2014. Perkembangan musik reggae. Perkembangan musik reggae. Tersedia pada http://adibfajar.blogspot.com. Diakses pada tanggal 28 Agustus 2014 pukul 09.30.

Gerungan. 2004. Psikologi Sosial. Bandung: PT. Refika Aditama.

H, De Vos. 1969. Pengantar Etika.Yogyakarta: PT. Tiara Wacana Yogya.

Hadiwardoyo, Purwa. 1990. Moral Dan Masalahnya. Yogyakarta: Kanisius.

Hidayatullah, Rizki. 2014. Inilah perkembangan musik Indonesia. Tersedia pada http://rizkyattyullah.blogdetik.com /index.php. Diakses pada tanggal 28 Agustus 2014 pukul 09.30.

Http://www.introlirik.com/12941/d/den-basito/den-basito-gajah-kupu-kupu.htm.

Diakses pada tanggal 20 Februari 2015 pukul 16.35.

Http://id.wikipedia.org/wiki Nilai Sosial. Diakses, 28 Agustus 2014 Pukul 09.30 Lilik. 2012. Definisi Nilai dan norma. Tersedia pada http://my-worldly2k.blogspot.com. Diakses pada tanggal 28 Agustus 2014 pukul 09.30.

Muhammad. 2014. Metodologi penelitian bahasa. Jogjakarta: Ar-Ruzz Media.

Poespoprodjo. 1988. Filsafat Moral. Bandung: Cv. Remadja Karya. 1999. Filsafat Moral. Bandung: Cv. Pustaka Grafika.

Sutejo dan Susanto Happy. 2010. Filsafat Ilmu. Ponorogo: P2mp Swpectrum Press. 
Widyastuti,Yeni. 2014. Psikologi Sosial. Yogyakarta: Graha Ilmu.

Zamroni, Mohammad. 2009. Filsafat Komunikasi Pengantar Ontologis, Epistemologis. Yogyakarta: Graha Ilmu.

Zona. 2014. Nilai sosial pengertian jenis sumber. Tersedia pada http://www.zonasiswa.com. Diunduh tanggal 28 Agustus 2014 pukul 2014. 